\title{
A Middle School's Approach to Developing an Effective School Work Culture
}

3y Edward W. Chance, Craig Cummins, and Fred Wood

The ultimate goal for any school administrator must be to develop an educational culture that establishes norms, behaviors, attitudes, and expectations. Only with the development of an effective work culture can schools and those within them achieve their full potential.

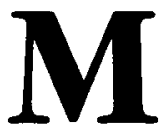

uch has been written during the past few years about the ongoing effort by educators to create effective schools. Ron Edmonds (1982) identified a series of correlates, including school climate, that are related to schools becoming more effective. During the early 1980s, the concept of school climate was seen by many as related to issues of school discipline and safety. The effective schools movement during that decade also focused on increasing cooperation among faculty and staff members and administrators.

Schools are now moving past this rather limited concept and have begun to view school climate as a component of school culture. Cooperation is now seen as a point on a continuum, with an ultimate goal of collaboration. We are beginning to view the establishment of a collaborative school work culture as a way to bring about significant school improvement and change.

Before examining how to develop a collaborative school culture, it is important to understand what we mean by the term. Cunningham and Gresso (1993) indicate that the culture of a school includes its "organizational values, ideals, attitudes, and beliefs" (p. 20). Sashkin and Walberg (1993) indicate that one of the key leadership roles for a principal is to

Edward W. Chance is professor of educational administration and higher education, University of Nevada, Las Vegas; Craig Cummins is principal of Altus (Okla.) Middle School; and Fred Wood is professor of educational leadership and policy studies, University of Oklahoma, Norman. 
establish a school culture for continuous improvement and increased productivity.

\section{A Culture for Continuous Improvement}

The desire to establish an effective school work culture both implies and necessitates a system for continuous improvement on the part of the school and its members. Whether this means a continuous struggle between reforming and recharging, as Sashkin and Walberg (1993) suggest, is not as important as the creation of a school work culture that exhibits certain identifiable characteristics.

Those characteristics include norms, expectations, behaviors, and outcomes that focus on a variety of elements ranging from trust to a willingness to experiment to open communication to a level of increased collegiality (Saphier and King, 1985). Cunningham and Gresso (1993) further support the importance of a positive school work culture by indicating that "the view people take of their jobs, organizations, and clients is ... most often created by a combination of culture and management" (p. 261).

A positive, effective school work culture represents commonly shared values, rituals, ceremonies, stories, and an internal cultural network that values heroes such as an extraordinary teacher, coach, or administrator (Sashkin and Walberg, 1993). The school principal has a tremendous impact on the establishment of a school work culture by understanding and developing the various components and characteristics of culture in his or her school.

A principal can use certain types of activities and approaches to leadership to make a significant We are beginning to view the establishment of a collaborative school work culture as

a way to bring about significant school improvement and change. difference in establishing a desirable school work culture. The remainder of this article describes some of these activities and approaches by discussing the success of one middle school in creating an effective school work culture.

\section{Activities That Promote School Culture}

Altus Middle School, located in far southwestern Oklahoma, has 718 sixth and seventh grade students and a faculty of 30 core subject teachers who work in teams. Additional staff members represent special education, teachers of electives, and librarians. The school has been pursuing the develop- 
ment of a positive, productive school work culture for several years. Two primary teams of teachers work together to oversee this process, with one focusing on vision and the other on curriculum.

One of the first activities used to promote a shared work culture was involving the faculty in creating an educational vision for the school. This shared vision represents common values and facilitates the planning process for the school; it provides a sense of direction and differs significantly from the school mission.

A mission represents what a school currently does, while a vision identifies where a school wishes to be in the future. A shared vision provides a focus for school personnel and results from an intensive process of selfevaluation, consensus building, and identification of strengths, weaknesses, and needs by stakeholders for the school (Chance, 1992).

The vision monitoring team has two responsibilities:

- To plan and implement activities that will enhance the achievement and actualization of the school's shared vision

A mission represents

what a school currently

does, while a vision

identifies where a

school wishes to be in

the future.

- To continuously collect and review school-related data that function as part of the ongoing evaluation of the school's movement toward collaboratively established short and long-term improvement goals.

The 11-member curriculum team is composed of five core subject teachers, a special education teacher, a fine arts representative, the librarian, the teacher of the gifted and talented, and the principal. The committee meets on a monthly basis and closely monitors and updates curriculum offerings. This committee is crucial since everything that takes place within the school affects learning, and learning and school culture are closely tied with the effort to actualize the school's shared vision.

A key to the success of these two teams has been the development of a level of mutual trust among the faculty and staff members and the school administrators. Some simple operational rules that have allowed mutual trust to grow and flourish include:

- People are important and should be listened to and recognized.

- Feelings are important so any criticism should always be focused on issues and ideas, not on individuals.

- Feelings, behaviors, and concerns should be openly, freely acknowledged and discussed.

- Honesty is a valued commodity among the "family" members at Altus Middle School. 
- We all learn from doing things together, deciding on issues as a group, and analyzing ideas that create an effective school work culture.

In addition to these agreed-upon rules, which really are behavioral norms and expectations, certain tactics and approaches will help to ensure the success of team and faculty meetings. School personnel are inundated with meetings so it is important that they be useful and relevant. Some simple approaches that work for meetings are:

- Provide an adequate meeting room for any team/faculty meeting.

- Provide adequate time for team meetings, which may necessitate schoolpaid released time.

- Prepare and gather any necessary data prior to the team/faculty meeting.

- Clearly articulate team/faculty meeting tasks and goals.

- Recognizing that people often select roles at meetings that may hinder or help its success, prepare leadership strategies that initiate active participation, stimulate thinking, and create interest and support for the school work culture.

All school meetings should have a goal of continuous improvement of the school work culture. This should hold true for all teaching team meetings as well as general faculty meetings.

Another aspect that has a great impact on the creation of a school work culture at Altus Middle School is faculty mentoring and peer coaching, which reinforce the norms and expectations of collaboration and peer support. Mentoring and peer

At Altus Middle School

a significant part of

the school work culture

is the belief that

teachers, both individ-

ually and as a group,

know what they need

for their professional

growth. coaching activities include:

- Establishing assistance committees for first-year teachers. Each new teacher is assigned a mentor and has the assistance of the principal and a university professor to help him or her through the initial year of teaching. - Assigning mentors to all new teachers in the school, including those who are not new to the profession

- Supporting teacher instructional experimentation that may have a positive impact on student learning through the use of teachers who coach their peers

- Providing a variety of instructional skills enhancement opportunities such as inservice education, observation of master teachers, attendance at professional conferences, and the development of strategies for teacher selfevaluation. 


\section{Grade Level Teams}

At Altus Middle School a significant part of the school work culture is the belief that teachers, both individually and as a group, know what they need for their professional growth. Given this belief, the role of the principal is to facilitate such growth by providing teachers with released time when needed, financial support when possible, and opportunities to make appropriate professional decisions about their staff development. Grade level teaching teams are often allowed to plan and develop inservice activities to meet their educational and professional needs. Teachers in this school need not all participate in the same inservice, but rather may personalize their professional growth activities.

Empowering grade level teaching teams to make instructional decisions has had a positive impact on the school work culture. At Altus Middle School, teaching teams are expected to plan and deliver instruction to approximately 125 students. Each team decides how it will deliver that instruction. The only constraints are that decisions about instructional practice must mesh with schoolwide goals.

Grade level teams can be as creative or as traditional as they wish in their instructional approach, which means each team spends a great deal of time discussing their students and making teaching decisions. To facilitate successful team planning certain organizational strategies and beliefs have been established. These include:

- Each grade level team is provided with a common daily planning time.

- Each grade level team has a regular meeting time with the principal and school counselor who serve as consultants.

- Grade level team meetings are used to create a sense of family by providing both formal and informal opportunities for social interaction and team building.

- Grade level team meetings provide a time to exchange ideas and plan for teaching their students.

- Grade level team meetings provide an opportunity to meet as a group with concerned parents and students.

- Grade level team meetings provide time to discuss the learning and instructional needs of individuals and groups of students assigned to the team.

Each grade level team exerts a tremendous impact on the school work culture because much of it is created by their daily professional actions and decisions. Each team may elect to use different instructional approaches; the only real constraints are those provided by the teachers themselves through decisions made by their colleagues on the vision monitoring and curriculum teams. 


\section{The Role of the Principal}

The principal must exhibit some specific behaviors throughout this entire effort to create an effective school work culture. The principal must trust the faculty and staff, and must provide the support that allows the faculty members and teams to be successful in their endeavors. At Altus Middle School, the administrators exhibit the following attributes that directly contribute to an effective school work culture:

- Creating open two-way communication that supports extensive facultyadministration interaction

- Developing a caring, listening, and hearing environment

- Being willing to run interference for faculty members and teams with the central office

- Being willing to modify the current school structure to allow for a more productive educational process

- Empowering teachers by words and by actions

- Monitoring committees and grade level teams to ensure they take responsibility for their decisions and tasks while working toward the creation of an effective school work climate and implementing improvements in practice.

The principal must adopt a new approach to school leadership. Faculty and staff members must become active partners in the educational process. All those involved in the education of students must help to develop, understand, accept, and support the agreed-upon direction and vision. There must be a willingness to monitor, collect data, and evaluate on a continuous basis.

The principal must practice new behaviors that call for him or her to be a partner, a facilitator, a negotiator, and a resource manager while continuously providing protection for others in the school who are seeking to redefine and strengthen the school work culture. When necessary the principal must lead, empower, or cajole.

The principals at Altus Middle School have established ways of operating that have resulted in an effective work culture, a culture in which:

- Teachers and administrators work collaboratively to determine the vision and improvement goals for their school.

- Teachers have control and responsibility for school improvements and the curricula in their schools.

- Meetings are organized in ways that reinforce and value listening, honest communications, group learning, shared decision making, and collaboration.

- Teachers are responsible for helping their peers improve their instructional practices. 
- Teachers feel and are empowered to make decisions about their own professional growth.

- Teams of teachers are expected and able to determine the best ways to plan and instruct their students.

- Principals are viewed and serve as facilitators and collaborators with teachers with a focus on creating a positive, effective learning environment for all students and adults in the school.

The ultimate goal for any school administrator must be to develop an educational culture that establishes norms, behaviors, attitudes, and expectations like those being developed at Altus Middle School. Only with the development of an effective work culture can schools and those within them achieve their full potential. $\sim B$

\section{References}

Chance, E. W. Visionary Leadership in Schools. Springfield, Ill.: Charles C. Thomas, 1992.

Cunningham, W. G., and Gresso, D. W. Cultural Leadership: The Culture of Excellence in Education. Boston: Allyn and Bacon, 1993.

Edmonds, R. R. "Programs of School Improvement: An Overview." Educational Leadership. December 1982.

Saphier, J., and King, M. "Good Seeds Grow in Strong Cultures." Educational Leadership. March 1985.

Sashkin, M., and Walberg, H. J., eds. Educational Leadership and School Culture. Berkeley, Calif.: McCutchan, 1993.

\section{Seniors in Academic Programs}

Enrollment in academic programs declined from 46 percent to 39 percent between 1972 and 1980 , but rose to 48 percent by 1992, according to a report on trends among high school seniors. The report presents information about seniors in 1972, 1980, and 1992, and examines trends in areas such as course taking and tested achievement. The percentage of seniors in vocational programs declined from 22 to 12 percent between 1972 and 1992, and the proportion of seniors in general education programs rose from 32 to 40 percent.

The National Education Longitudinal Study of 1988: Trends Among High School Seniors, 1972-1992 (159 pp.) is available for $\$ 12$ from Superintendent of Documents, P.0. Box 371954, Pittsburgh, PA 15250-7954. 